University of Montana

ScholarWorks at University of Montana

Graduate Student Theses, Dissertations, \&

Professional Papers

1978

\title{
Perceived sex-role attitudes in self and other as a determinant of differential assertiveness in college males
}

Elizabeth Parker Hess

The University of Montana

Follow this and additional works at: https://scholarworks.umt.edu/etd

Let us know how access to this document benefits you.

\section{Recommended Citation}

Hess, Elizabeth Parker, "Perceived sex-role attitudes in self and other as a determinant of differential assertiveness in college males" (1978). Graduate Student Theses, Dissertations, \& Professional Papers.

5727.

https://scholarworks.umt.edu/etd/5727

This Thesis is brought to you for free and open access by the Graduate School at ScholarWorks at University of Montana. It has been accepted for inclusion in Graduate Student Theses, Dissertations, \& Professional Papers by an authorized administrator of ScholarWorks at University of Montana. For more information, please contact

scholarworks@mso.umt.edu. 
PERCEIVED SEX-ROLE ATTITUDES IN

SELF AND OTHER AS A DETERMINANT OP

DIFFERENTIAL ASSERTIVENESS IN COLLEGE MALES

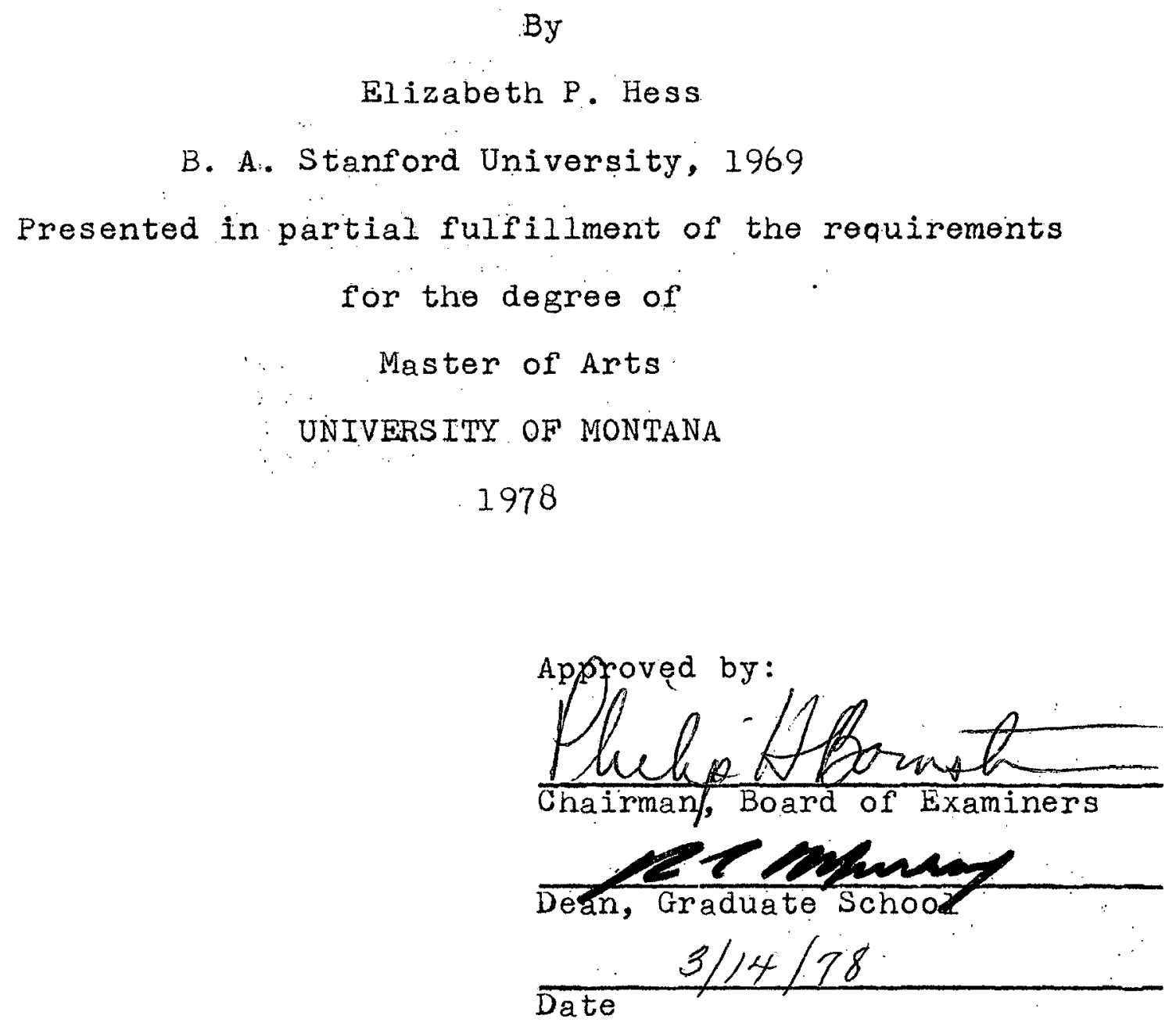


UMI Number: EP41194

All rights reserved

INFORMATION TO ALL USERS

The quality of this reproduction is dependent upon the quality of the copy submitted.

In the unlikely event that the author did not send a complete manuscript and there are missing pages, these will be noted. Also, if material had to be removed, a note will indicate the deletion.

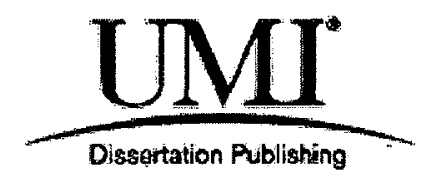

UMI EP41194

Published by ProQuest LLC (2014). Copyright in the Dissertation held by the Author.

Microform Edition (c) ProQuest LLC.

All rights reserved. This work is protected against unauthorized copying under Title 17, United States Code

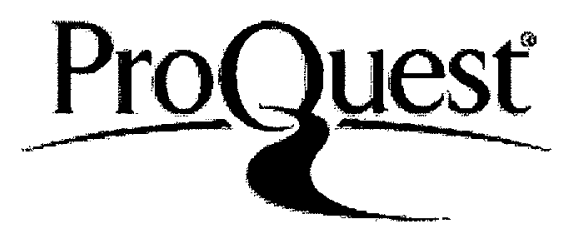

ProQuest LLC.

789 East Eisenhower Parkway

P.O. Box 1346

Ann Arbor, Ml $48106-1346$ 
Hess, Elizabeth P., M. A., 1978 Psychology

Perceived Sex-Role Attitudes in Self and Other as a Determinant of Differential Assertiveness in College Males ( $52 \mathrm{pp.}$ )

Director: Phillip H. Bornstein<smiles>c1ccccc1</smiles>

Three possible factors influencing the amount of assertion shown towards a female by college males were investigated, using a female confederate in an unobtrusive assertiveness situation. Degree of anxiety experienced, as a function of the amount of assertiveness shown and subjects' attitudes towards women, was also assessed. Subjects with either traditional or profeminist attitudes towards women observed the confederate dressed in either a feminine or nonfeminine manner, and exhibiting either feminine or nonfeminine behavior. Subsequently, subjects were placed in a situation in which making a reasonable request, one form of assertive behavior, was unobtrusively agsessed. Immediately afterward each subject filled out an anxiety inventory.

Subjects were least assertive towards the confederate in the feminine appearance-feminine behavior condition, most assertive in the nonfeminine appearane $\theta-$ feminine behavior condition, and showed an intermediate amount of assertion in the other two conditions. There were no significant differences found in assertion between traditional and profeminist subjects, or on the anxiety measure. 
TABLE OF CONTENTS

Page

ABSTRACT. . . . . . . . . . . . . . . . .

LIST OF TABLES AND FIGURES.............. iv

Chapter

I. INTKODUCTION.................. I

Situational Factors in Assertion

Sex-Role Expectations and Aggression

Theories of Sex-Kole Differences in Behavior

Sex-Role Expectations and Assertion

Purpose of the Present Investigation

II. METHOD....................... 15

subjects

Apparatus.

Procedure

III. RESULTS ..................... 22

IV. DISCUSSION................... 25

REFERENCE NOTES.................. 32

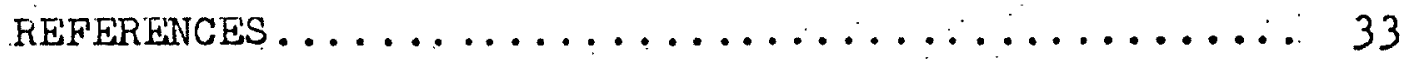

TABLES AND FIGURES $\ldots \ldots \ldots \ldots \ldots \ldots \ldots \ldots \ldots \ldots . \ldots$

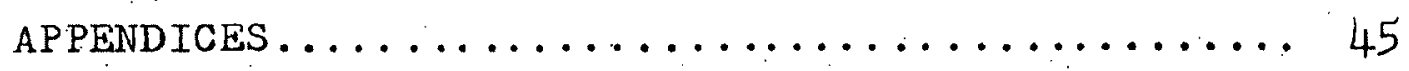




\section{LIST OF TABLES AND FIGURES}

Table

1. Analysis of Variance: Unobtrusive Measure of Assertion................... 40

2. Mean Assertion Scores of Subjects Grouped by Levels of Factors.................. 41

3. Mean Assertion Scores for Subjects Grouped by Appearance, Behavior, and Subjects' Attitudes...................... 42

4. Analysis of Variance: Anxiety Measure....... 43 Figure

1. Mean Ratings of Assertion Showing the Interaction Effect of the Behavior Factor with the Appearance Factor................. 44 
CHAPTER I

INTRODUCTION

Situational Factors in Assertion

McFall and Marston (1970) have outlined several problem areas in assertion research, including the need for specificity in describing response classes, a clearer identification of the components of assertive behavior, and the development of reliable measures of assertiveness, preferable in real life situations. Although early researchers in the area were content with broad definitions of assertiveness (e. g. Wolpe \& Lazarus, 1966), more recently attempts have been made to specify separate response classes within assertive behavior Galassi, Deleo, Galassi, \& Bastien, 1974; Goldstein, Martens, Hubben, Van Belle, Schaaf, Wiersma, \& Goedhart, 1973; O'Connor, 1969). This trend has been encouraged by the failure of factor analyses of assertiveness inventories to yield a general factor (Bates \& Zimmerman, 1971; Gambrill \& Kichey, 1975, Lawrence, 1970). Response classes have included such abilities as saying "No" to unreasonable requests, asking favors, expressing positive and negative feelings, initiating conversations, and making self-enhancing rather than selfdenying responses and decisions in conflictual situations. 
In addition to variations in assertiveness due to response class, situational variables seem to play a large role in determining the degree of assertive behavior exhibited. (Eisler, Hersen, Miller \& Blanchard, 1975; Mischel, 1968). Eisler et al. found that both the sex and familiarity of the stimulus person affected the expression of positive and negative assertion by psychiatric patients. Furthermore, the social context influenced length of talking, amount of smiling, and latency of responding.

The specific influence of response class and situational factors must be taken into account in devising adequate measures of assertion. Of seven recent assertiveness inventories, only the Conflict Resolution Inventory (McFall \& Lillesand, 1971) and the Assertion Inventory (Gambrill \& Richey, 1975) have demonstrated validity and usefulness for screening and assessment. A large part of the difficulty with the other inventories appears to be due to failure to specify the response class precisely (Rich \& Schroeder, 1976). When contrived behavioral or role playing situations are used, results may be biased by the subjects' awareness that they are being observed, by demand characteristics, or by subjects' discomfort with playing roles (Rich \& Schroeder, 1976). However, carefully designed contrived but unobtrusive tasks have overcome these problems (e. g. Friedman, 1968; McFall \& Lillesand, 1971; McFall \& Marston, 1970; McFali \& 
Twentyman, 1973). This approach to measurement seems to of fer the highest likelihood of validity, but efforts must be made to control extraneous influences.

There is disagreement on the relationship between assertion and aggression. While some make little distinction between them (e.g. Salter, 1949; Wolpe, 1958), Lazarus (1971, 1973) and Alberti and Emmons (1.974) maintain that aggression differs from assertion in that the intent of aggression is to deny, humiliate, or depreciate others, whereas assertion attempts to convert adversary into advocate situations. This distinction seems to hinge on the appropriateness of the content of the response. For example, Rathus (1973) found that global encouragement of subjects to behave more aggres-. sively or assertively varied inversely with ratings of "niceness". But what constitutes "nice" behavior in one situation will not necessarily be considered "nice" or socially acceptable in another situation. This may be particularily true for assertive responses involving content which might be construed as aggressive. Different aggressive behaviors are considered appropriate for different ages and sexes. Sex-role stereotype research has shown that while assertive behavior may be desirable for males, it is considered undesirable for females. (Broverman, Broverman, Clarkson, Rosenkrantz, \& Vogel, 1970; Buss, 1971; Rosenkrantz, Vogel, Bee, Broverman, \& Broverman, 1968). 
Sex-Role Expectations and Aggression

Research with aggression indicates that sex of the victim and sex role stereotypes concerning the victim of aggression may also be an important factor in determining the porceived appropriateness of an aggressive response. Buss $(1963,1966)$ did research on aggression using a bogus learning experiment. The subject was informed that he was to act as a teacher, and that he must shock the learner in the situation when he made an incorrect response, selecting from among 10 levels of shock intensity. He found that men administered a higher level of shocks, but also that male victims received more intense shocks than their female counterparts. Taylor and Epstein (1967) did further research in the area using a similar procedure. Subjects were led to believe they were competing against an unseen male or female on a task involving reaction time: Before each trial, the subject would select one of five levels of shock, which was to be delivered to the other person if the subjects won. The subject was informed that the other person would also select levels of shock, which the subject would receive if he lost. At the time the shocks were administered a number would light up to show the level. of shock selected. Twenty-five trials were run for each subject in blocks of six trials each. On three random trials within each block, the subject "lost" and was shocked. 
With each succeeding block of trials, the average intensity of shocks administered to the subject increased. The three independent variables involved were sex of subject, sex of opponent, and amount of provocation (1evel of shock received). Dependent variables were amount of aggression shown (magnitude of shock the subject chose to administer) and basal skin conductance, used as a measure of stress. Subjects in the experiment became very emotionally involved, banging on the desk, cursing, and shouting threats to the unseen opponent. Despite verbal expressions of anger, both male and female subjects showed a greater rise in stress when the subject had a female opponent. Taylor and Epstein hypothesize that this was due to the strain of refraining from aggressive responding. Interestingly, the highest level of aggression obtained was for female subjects under high provocation conditions with a male opponent. Taylor and Epstein suggest that this was due to the perceived violation of social expectancy, which can be a strong incentive to aggression. Although these aggression studies indicate that the sex of the victim is an important variable in the degree of aggression elicited, one recent study has indicated that this may not be so when forms of aggression other than electric shock are used, such as noxious noise (Martinolich \& Sechrest, Note I). However, further research is needed to determine precisely. 
which forms of aggression do interact with sex of the victime, which do not, and the causative factors involved. One possible explanation for the difference in willingness to administer a noxious noise to a female victim, rather than a painful shock, could be that social expectations dictate that women should not be physically hurt, but there may not be any objection to making them somewhat uncomfortable in a way which would not be actually painful.

One field study has found that women are less likely than men to provoke aggressive responses from their victims after bumping into them, or cutting into line in front of them (Harris, 1973). In contradiction to the findings cited previously, both men and women have been found to honk at a woman blocking an intersection sooner and more often than at a man (Deaux, 1971, Doob \& Gross; 1968). Deaux hypothesizes that this due to the stereotype of "damned woman driver". Again it would seem that the social expectancies governing aggressive behavior may, in fact, be highly situation specific.

Two studies of aggression in children have found similar sex factors involved. In an experiment patterned after Taylor and Epstein, Shortell and. Biller (1970) found that upper middle class sixth graders gave loss noxious noise as a punishment to girls as victims than to boys. Girls rated boys who were aggressive as significantly less socially de- 
sirable than did boys performing the same rating. The girls also rated boys as showing more aggression than did boys performing the same rating task. In a study of verbal aggression, Sandidge and Friedland (Note 2) presented children with pictures of a conflict situation and asked tam what they would answer as either a boy or girl being aggressed:against. The sex of the aggressor in the pictures also varied. Both sex subjects answered less aggressively if the victim was a giri. Sandidge and Friedland hypothesize that subjects were assuming that a girl should not be attacked, but that if she were, she had a right to respond as aggressively as possible. This is similar to the conclusions of Taylor and Epstein (1967) and Shortell and Biller (1970).

Recent studies have also found that social expectancies involving women vary according to whether or not the women are perceived as holding traditional or pro-feminist attitudes (e.g. Goldberg, Gottesdiner, \& Abramson, 1975; Richmond \& Robertson, 1977). Kaleta and Buss (1973) investigated the effect that varying the characteristics of a female "victim" would have on the amount of aggression displayed towards her by male college students. Both the victim's: appearance and behavior were presented as either fominine or ronfeminine. In the feminine appearance condition the victim wore make up, a frilly dress, nylon stockings, and 
stylish shoes. In the unfeminine appearance condition, the same person wore no make up, pulled her hair back in a severe style, and wore baggy, somewhat sloppy clothing. Feminine behavior was represented by asking polite cuestions and showing concern for the feelings of others. Unfeminine behavior consisted of acting oblivious to others feelings and being more assertive in her statements. Using an experimental situation with shock being administered as part of a bogus teaching task, Kaleta and Buss presented each subject with one of the four possible combinations of appearance and behavior in the victim. Women who were feminine in both behavior and appearance received the least amount of shock. Women who were unfeminine in both behavior and appearance received the most shock. Women who were feminine in one respect but not the other received an intermediate amount of shock. Deaux (1976) hypothesizes from this study that

It appears that our society does have norms that say not $f$ ight against... But if the woman in auestion has chosen to forsake some parts of the feminine role...there is more chance that the potential aggressor will also forsake some of his normative beliefs. (p. 88) Young, Beier, Beier, and Barton (1975) investigated the effects of differences in men's attitudes towards women on their non-verbal expression of aggression. They view chivalry:as a social convention whose purpose is to promote a more predictable social climate. It would be 
likely, therefore, if a woman were to violate her sex-role stereotype and behave in an aggressive manner towards a normally chivalrous male, he would discontinue his chivalrous tactic and respond with more aggression himself in órder to communicate his distaste at being confronted with an unpredictable social situation. In their experiment Young et al. placed male college students into "pro-lib" and "anti-lib" categories on the basis of their responses (true or false) to the statement "You would really prefer that women play a more traditional role and take care of the home and children." The subject was given a padded club of the type used in sensitivity workshops with sensors imbedded inside it to measure the force of blows. Under the pretext of testing the equipment he was asked to engage in two hitting bouts with a female partner. During the first bout the female maintained a passive role, merely blocking the blows which the male gave. However, during the second bout she would take part aggressively, hitting the male subject at a fixed rate of attack. They found, as expected, that the pro-lib group were significantly more aggressive towards the woman in both bouts than the anti-lib group. Members of the anti-lib group made comments such as "Can't you get me a guy?" or "I can't hit her!" which add weight to the hypothesis that they felt unwilling to act aggressively towards a female. Both the pro-lib and the antilib group increased the amount of aggression significantly. during the female active bout, but the anti-lib men in- 
creased their aggression more.

From the results found in the two studies just described, it seems that not only does sex of participant neod to be taken into account as an important variable in determining the amount of aggression displayed, but the sex-role attitudes held by the participants or perceived as being held by them will also be a factor. In fact, one study (Borden, 1975 ) has. found that the perceived values of an observer in a shock aggression experiment (the observer was characterized as being part of either a pacific or an aggressive organization) caused significant differences in the level of shocks selected whereas the sex of the observer did not. But if the subject knew nothing about the observer except the observer's sex, than sex was a significant factor. Aggressive behavior was apparently a function of the subjects' expectations of approval for. such behavior, based on the inferred or explicitly stated values of the observer. Given no other information, women were inferred to be pracific. Theories of Sex-Kole Differences in Behavior. Most of the explanations for sex-role differences in behavior are based on social learning theory (e. g. Maccoby \& Jacklin, 1974; Mischel, 1966, 1970; Rotter, 1954), a cognitive-developmental approach (Kohlberg, 1966) or the 
developmental process of identification (e.g. Block, Von der Lippe, \& Block, 1973; Kagan, 1964). In social learning theory, the acquisition of sex-typed behavior uses the same learning principles as any other aspect of an individual's behavior, including the patterning of reward, nonreward, and punishment under specific contingencies." Learning occurs via modelling and the individual's own experience. Gradually the person learns socially approved behavior and comes to anticipate probable outcomes. Thus the individual can learn through inferred response consequences as well as actual events. However, sex-typed behavior which is learned is situation specific, like all learning (Mischel, 1966): In the cognitive-developmental framework, basic sexual attitudes are patterned by the child's cognitive organization of his social world along sex-role dimensions. This patterning stresses the observational learning of social roles via modelling by others. The child is constantly involved in the active structuring of his environment. His or her sexual identity is maintained by a motivated adaptation to the previously structured physical-social reality and by the need to preserve a stable and positive self-image (Kohlberg, 1966). Kagan (1964) posits the existence of a fundamental human motive to make one's behavior conform to a previously acquired standard. This standard becomes desirable via identification with 
models who possess a cluster of traits, expectation of affection and acceptance for possession of the trait cluster, and expectation that possession of the cluster will prevent social rejection. However, research done by Block et al. (1973) indicates that socialization and the acquisition of sex-role typing may occur independently of one another. For example, a person could have a highly masculine sex-role type but be only poorly socialized, as measured by the so scale of the CPI. Finally research done by Bem suggests that sex-role differences. may be best represented by seoing masculinity and femininity not as opposite ends of a single scale, but as two separate dimensions which can vary independently (Bem, 1976).

All of the theoretical explanations seem to agree that sex-role behavior and attitudes are useful for providing social expectancies which will increase the probability of positively reinforcing social interaction. However, these expectancies are situation specific, and probably far more complex than the simple dichotomy of male-female frequently used in past research in the area. With the increased impact of the women's movement in the 1970's, traditional sex-role stereotypes are coming into ouestion, but much more research is needed to determine the extent to which sex-role attitudes and behavior are really changing. 
Sex-Hole Expectations and Assertion

In the area of assertion, little research has been done concerning the differential impact of having a female rather than a male partner for assertive interactions, outside of the area of specific training in dating skills: Eisler, Hersen and Miller (1975) had 60 psychiatric patients role play assertive situations with either male or female partners who were either familiar or unfamiliar to them within the context of the role. Half of the situations involved positive assertive behaviors and half negative as sertion. Considerable sex differences were found, including longer talking to females, more smiles to females, more likely to request that a female change her behavior, more likely to deliver praise and appreciation to a female, greater ratio of speech disturbances speaking to males, more likely to comply to the negative request of a male, and more likely to perform a favor for a male. Eisler et al. conclude that an individual's assertive behavior depends on the social context. Overall they found that men are more likely to stand up for themselves with women than men, and more likely to show appreciation towards women. They point out that this was not a normal population and that further research needs to be done with varying populations to investigate the generalizability of these findings. 
Purpose of the Present Investigation

The purpose of this study was to use a contrived situation as a measure of assertion in the area of the ability to make requests (Lazarus, 1973). The differing impact of sex-role attitudes held by male, college student subjects was assessed. In addition, feminine and nonfeminine appearance and behavior on the part of a female partner was varied in the assertion situation to assess the effect of those factors. Finally, a measure of anxiety was administered immediately after the subject had been confronted with the assertion situation.

The following hypotheses were tested:

1) Subjects with profeminist sex-role attitudes are more assertive than subjects with traditional sex-role attitudes.

2) Men are most assertive towards a woman who both appears and acts in a nonfeminine manner and least assertive towards $a$-woman who both appears and acts in a feminine manner.

3) Men who have just acted assertively score higher on an anxiety measure than men who have refrained from acting assertively.

4) Traditional attitude men score higher on an anxiety measure than pro-feminist attitude men. 
CHAPTEK II

METHOD

\section{Subjects}

Subjects were 80 male college students enrolled in an introductory psychology class at the University of Montana. The entire class was administered a short version of the Attitudes toward.Women scale (AWS) under the pretext of gathering normative data (Spence, Helmreich, \& Stapp, 1973). Men scoring above the median were assigned to Group A. (the profeminist group). Men scoring below the median were assigned to Group B (the traditional group). Group rosters were posted together with sign-up sheets for the experiment, stating that group membership pertained to certain data to be collected concerning self-awareness and vocational interests. First names were posted by initial only in order to disguise the fact that only males would be subjects (see Appendix C for further detail). Subjects should have had no awareness of the connection between the AWS testing and this study, as the personnel involved were different in the two situations.

In a preliminary study, the AWS was administered to 30 undergraduate students, and was found to correlate .58. with a measure of self-rating of pro-feminist attitudes, .65 with support of the Equal kights Amendment, and .66 with an estimate of lack of differential treatment of women in an assertive situation, for male subjects (see Appendix 
E for instrument used). The mean score for males was 52.2 , with a possible maximum of 75 for the most profeminist attitudes.

\section{Apparatus}

An unobtrusive measure of the subject's assertion in making a request (Cummins, Holombo, \& Holte, Note 3) was used. Each subject was requested to enter an office to fill out a questionnaire. The office contained two desks and three chairs. A female confederate was seated at one desk filling out the same auestionnaire that was given to the subject. The confederate was instructed to pay no attention to the subject. She had her feet propped up on a second chair. The third chair. was placed. at the side of the available desk, with 28 American Psychologist journal issues piled up on it in such a manner as to reouire considerable effort to remove them. Thus the subject was ablo to obtain a chair either by asking the confederate to remove her feet or by removing the journals. The subject could also choose to sit on the desk or the floor while completing the questionnaire. The subject was rated on a five point overall assertiveness scale by the confederate and another unobtrusive observer. This rating was based on descriptions of assertive behavior in Wolpe and Lazarus (1966): Specifically, the subject was scored 1 if he moved the books with less than five seconds hesitation; 
scored 2 if he moved the books, but hesitated at least five seconds before doing so; scored 3 if he asked the confederate to move her feet, but hesitated more than five seconds and exhibited a lack of firm effect, poor eye contact, and/or low voice volume; scored 4 if he asked the confederate to move her feet, but in a manner still less than completely assertive; and scored 5 if he asked the confederate immediately to move her feet in a selfassured manner, using good affect, eye contact, and voice volume. The two observers were given considerable practice in using this scale before the experiment began in order to establish an acceptable level of inter-rater reliability: In previous use, (Cummins, Holombo, \& Holte, Note 3) none of 50 subjects gave any indication in a postexperimental questionnaire of awareness of the true purpose of the chair and desk arrangement. The task also appeared to be at a good level of difficulty to discriminate assertive from nonassertive subjects, with 12 of 23 males and 11 of 27 females having asked the confederate to remove his feet.

In this study, the unobtrusive measure of assertion described above was preceded by a staged interaction between the experimenter and the confederate. As the subject first entered a different experimental room, he saw the experimenter talking to a female college student confederate who 
appeared to be another subject for the experiment. For one half of the subjects the confederate dressed in a feminine manner (dress, make up, feminine hair style, and stylish shoes). For the other half of the subjects she dressed in a nonfeminine manner (jeans, loose shirt, jacket, no make up, hair pulled back, and sturdy shoes.)

Within each of these appearance conditions the confederate also varied her behavior so as to act in a feminine manner half of the time, and in a nonfeminine manner half of the time. Feminine qualities were selected from survey research concerning sex-role stereotypes. only qualities considered positive were chosen. Nonfeminine qualities were chosen which represent the absence of the feminine qualities, rather than masculine qualities, in consideration of Bem's findings that masculinity and femininity are more likely to be separate entities than opposite poles on a continuum (Bem, 1976). Nonetheless, the nonfeminine qualities chosen were very similar to some of those found to be positively valued masculine traits (kosenkrantz et al., 1968). The feminine traits selected were: 1) refrains from using harsh language, (Bem, 1976; Kosenkrantz et al., 1968) 2) quiet (Kosenkrantz et al., 1968) or soft spoken (Bem, 1976) 3) expresses tender feelings (Rosenkrantz et al., 1968) or tender (Bem, 1976) 4) aware of feelings of others (Kosenkrantz et al., 1968) or sympathetic and understanding (Bem, 1976) 5) appreciates art and literature (hosenkrantz et al., 1968): 
The nonfeminine traits corresponding to the above were: 1) uses harsh language 2) speaks loudly and forcefully 3) does not display emotion, impassive 4) does not display awareness of others' feelings 5) likes math and science. Scripts were prepared for an interaction between the confederate and the experimenter which would display either the feminine or nonfeminine traits described above (See Appendix A). Both the appearance conditions and the behavior conditions were rated prior to the study by ten graduate students in Clinical Psychology, using a Likert scale to evaluate the presence of each of the characteristics described above (See Appendix B). Katings of behavior were made after viewing a videotape of the confederate engaging in each of the two behavioral scripts with an experimenter, while wearing neutral clothing. hatings of appearance were made after viewing a videotape of the confederate dressed as she would for each of the two appearance conditions. A T-test of the ratings indicated a significant difference ( $p .01$ ) between the nonfeminine and feminine conditions of each factor.

Procedure

On alternating days the confederate, who was the same person throughout the study, dressed for either the feminine or nonfeminine appearance. Within each day of the study, the confederate alternated between feminine and non- 
feminine behavior after each two subjects. The sign up sheet was constructed in such a way that every other subject was a member of the traditional attitudes toward women group, alternating with profeminist group members. The experimenter, the unobtrusive observer, and the confederate were uninformed as to the reason for these two groupings, being told simply that 80 males were to be tested. (See Appendix D for details of scheduling of the various treatment conditions.)

As each subject entered the first room used for the study, the experimenter and the confederate enacted either the feminine or nonfeminine script, under the pretext that the confederate was also a subject and that the experiment was running late. After the confederate was sent across the hall to the room to be used for the unobtrusive measure, the experimenter asked the subject the same ouestions he just asked the confederate (see scripts, Appendix A). He then gave the subject the State-Trait Anxiety Inventory (Speilberger, Gorsuch, \& Lushene, 1970) to fill out and directed him across the hall to the room where the confederate and the unobtrusive observer were waiting (The unobtrusive observer was located behind a one-way mirror partially covered with plywood.). They recorded their rating of the subject's overall assertiveness, and then the confederate left, after seeming to finish her copy of the 
anxiety inventory. When the subject had finished the inventory and returned to the original room, he was debriefed by a second experimenter, using the procedures suggested by Aronson and Carlsmith (1969) for postexperimental interviews. It was decided before the experiment began that any subjects would be eliminated from the study who realized that the subject was intentionally acting in an extreme feminine or nonfeminine manner and that he was being watched to see how he would react to this situation. The second experimenter, who was kept unaware of the assertion scores obtained by the subject, determined after the interview whether that subject should be eliminated. 


\section{CHAPTER III}

\section{RESULTS}

Measures taken to ensure reliability and validity of the data appear to have been auite successful. When the introductory psychology class took the short form of the Attitude toward Women Ścale; a subject pool of 133 males. was obtained with a mean score of 48.7 . The median score of 48 was used as the cut off score to separate Group A from Group B. In addition, a Pearson product moment correlation of $r .96$ was obtained between the assertion scores as rated by the confederate and the unobtrusive observer, indicating a high level of inter-rater reliability. Finally, none of the subjects met the criterion for elimination from the experiment in the post-experimental interview. Although 11 subjects indicated that they thought there was something strange about the confederate's behavior and suspected this was connected with the experiment, they were unable to surmise the reason for her actions. These 11 subjects were approximately evenly distributed among the treatment groups.

There were eight treatment groups, each with 10 subjects. Data were analyzed using a $2 \times 2 \times 2$ analysis of variance, with subjectsi assertion scores as the dependent variable. The three factors were subjects' attitude towards women (traditional or pro-feminist), appearance 
(feminine or nonfeminine), and behavior ( $f$ eminine or nonfeminine). A significant main effect was found for the appearance f'actor, where subjects assertion scores were significantly higher ( $p .05)$ for the nonfeminine appearance groups ( $x$ 3.263) than for the feminine appearance groups ( $X$ 2.475). A significant interaction effect was also found between the appearance and behavior factors (p. .05) (See lable 1 and Figure 1). A Neumann-Keuls Analysis of the data revealed that all comparisons were significantly different except that between the nonfeminine appearance, nonfeminine behavior group and the feminine appearance, nonfeminine behavior group. The highest mean assertion score was obtained by the nonfeminine appearance, feminine behavior group ( $x$. 3.925), followed by the feminine appearance, nonfeminine behavior group ( $x$ 2.825), the nonfeminine appearance, nonfeminine behavior group ( $(2.600)$, and the feminine appearance, feminine behavior group $(X 2.125)$ (See Figure 1 ). The crossed nature of this interaction may well have precluded the finding of significant results for the main factor of behavior. Fror a summary of mean scores for all factors and levels of factors, see Tables 2 and 3. Insert Tables $1,2 \& 3$ and Figure 1 about here An additional $2 \times 2$ analysis of variance was performed using State scores from the State-Trait Anxiety Inventory 
as a dependent variable. In this analysis the two factors were attitude toward women (traditional or pro-feminist) and assertiveness (assertive or non-assertive)... As indicated in Table 4, the results of this analysis were not significant.

Insert Table 4 about here


CHAPTER IV

DISCUSSIONN

The first hypothesis to be tested by this study was that subjects with pro-feminist sex-role attitudes would be more assertive than subjects with traditional sex-role attitudes. Although results in this direction were found, the difference between groups was not significant. This is contrary to the findings of Young, Beier, Beier, and Barton (1975) in a similar experiment using physical aggression rather than assertion as a dependent measure. There are several possible explanations for this discrepancy. Firstly; a reluctance to be assertive towards women may not be as deeply entrenched a social expectancy among traditional males as is their reluctance to show physical aggression. Secondly, it is possible that a competing social expectancy exists among traditional males: They may foel more free to stand up for themselves with women than with men (this is suggested by the results of Eisler, Hersen \& Miller 1975 who found that male subjects "stood up for themselves more" in roleplayed assertion situations involving women than situations involving men.) This competing expectancy could temper the traditional men's tendencies to refrain from assertive behavior towards women. There is also a third, 
methodological consideration. By defining the two groups of subjects simply as those above and below the mean, rather than a more polarizing definition such as the top and bottom thirds of the subject pool, a quite rigorous comparison was attempted. It is possible that by eliminating those subjects towards the center of the continuum, significant results might have been obtained. However, Young, Beier, Beier, and Barton (1975) were able to obtain a significant difference using a dichotomous division of their subject pool similar to the one used in this study. Thus this methodological explanation seems unlikely. It would appear once again that assertion is a highly situation specific behavior, and that physical aggression with a padded club is simply a distinct response category from making a reasonable request. This is indicated by the fact that one behavior is labeled "aggressive" while the other is labeled "assertive", but the variety of significantly different response categories is probably far too great to be adequately distinguished by only these two terms.

The second hypothesis to be tested was that men would be most assertive toward a woman who both appeared and dressed in a nonfeminine manner and least assertive toward a woman who both appeared and acted in a feminine manner. Hesults involving these factors revealed a 
complex pattern. There was a significant interaction between the factors of appearance and action. If the confederate was acting in a feminine manner, there was a great difference in the amount of assertion demonstrated depending on how she dressed.: However, if she was behaving in a nonfeminine manner, her appearance caused an insignificant difference in the amount of assertion shown: It would be productive to replicate this study with the factor of appearance held neutral. The nonsignificance of the behavior factor in this study may well be due to the crossed interaction effect which occurred.

The most assertion was shown towards the confederate when she behaved in a feminine manner but dressed in a nonfeminine manner. It is possible that in this condition she became the victim of the conflicting social expectancies described in the discussion of the first hypothesis. Since she was dressed in a nonfeminine manner she did not elicit the tendency to refrain from acting assertively toward a woman. Moreover, since she was acting in a feminine manner (including such oualities as being quiet, soft spoken, tender, sympathetic, and understanding (Bem, 1976; Rosenkrantz et al.), she may well have elicited the expectancy that "here is someone with whom I can easily stand up for myself" (see Eisler, 
Hersen \& Miller, 1975).

In fact, this second expectancy may be as much due to the nonassertive nature of typically feminine behavior as to anything else inherently "feminine" about it. A comparison of the qualities typically considered to be feminine with qualities considered to be components of assertive behavior reveals that they are almost exactly opposite. When the confederate acted in a nonfeminine manner, she also may well have conveyed the message that she was an assertive individual, one less likely to respond in ready acquiesence to another's request than a nonassertive individual. Certainly several subjects who encountered the confederate's nonfeminine behavior made statements during the debriefing indicating their reluctance to deal with her (e. $g$. "Boy, the way she was acting, I sure wasn't goint to ask her to move her feet!"). Another study with a male confederate acting in an assertive or nonassertive manner might separate out this assertion factor from the overall sex-role expectancy factor.

In confirmation of the last half of the second hypothesis, less assertion was shown towards the confederate when she both appeared and behaved in a feminine manner than in any other condition. It would seem that if there are two conflicting expectancies, the expectancy that a man should not be what he perceives to be "aggressive" 
towards a woman is more powerful than the expectancy that he should be able to stand up for himself with her. Obviously this type of interaction is highly situationally determined.

The results of this study did not support the last two hypotheses, that assertive subjects would score higher on an anxiety measure than nonassertive subjects and that traditional, assertive subjects would score higher than pro-feminist, assertive subjects. It is likely that acts of assertion towards women are not as anxiety provoking as acts of physical aggression. Other possible explanations are that the instrument was not sensitive enough to record accurately any changes in anxiety which did occur, and/or that there were too many uncontrolled extraneous variables involved in this analysis to obtain valid results.

The results of this study reemphasize the crucial need. to further examine situational determinants of assertive behavior. It seems that a person confronted with a situation potentially calling for assertion may be influenced in his decision on how to bohave not only by the type of response called for, but by attributes of the other person or persons involved which may set up certain social expectancies. The sex of the other individual may be one such attribute, but it appears that even more specialized disstinctions such as manner of dress may have a significant 
effect on assertive behavior.

Various further research investigations in this area have been suggested above. It should be noted that the unobtrusive measure of assertion employed in this study proved to be an exceptionally useful and efficient research tool. It is inexpensive, easy to set up, ruick to. administer, highly successful in deceiving subjects, and produces behavior by the subject which can be evaluated with high inter-rater reliability after only a brief training period for observers. It also avoids the drawbacks of paper and pencil inventories, contrived behavioral situations, or role playing.

Besides pointing out the specificity of assertive behaviors, this study suggests that current sex-role expectancy effects in the area of aggression and assertion may be more complex than previous studies such as Young, Beier, Beier, and Barton (1975) or Kaleta and Buss (1973) would indicate. It would seem that a woman who would prefer not to be asserted against should choose to be consistent in her manner of appearance and behavior. Especially, she should not choose to relincuish the "protective coloration" of typically feminine dress unless she has learned effective techniques of assertion or other forms of nonfeminine behavior to accompany her appearance. Her choice of feminine or nonfeminine dress may actually signal to others a broader choice on her part between abiding 
by traditional feminine stereotypes or expanding into a more androgynous stance. Relinauishing the feminine stereotypes may well aiso mean relincuishing receiving the gentler treatment usualiy reserved for the "weaker" sex. However, the nonfeminine behavior conditions in this study seems to suggest that this heightened aggression and/or assertion can be limited if the woman does not present herself in a way giving the impression that she would be an easy victim. Given the increase in anti sex-discrimination legislation, visible impact of the women's movement, higher incidence of working women, etc., many traditional stereotypes concerning women may become weakened whether an individual woman desires it or not. If this is the case, clinicians should be aware of the need to help women whose own behavior is still ouite traditional to cope with the new social expectancies that may arise. 
Keference Notes

1. Martinolich, M., \&echrest, L. Physical aggression as a function of sex of subject, sex of target, and subject's attitude toward the role of women. Paper presented at meeting of Southeastern Psychological Association, March, 1975 .

2. Sandidge, S. \& Friedland, S. J. Sex-role-taking and aggressive behavior in children. Paper presented at the meeting of the Society for Research in Child Development, Philadelphia, 1973.

3. Cummins, D. E., Holombo, L. K., \& Holte, C. S. Target specificity in a self report measure of assertion. Unpublished manuscript, University of Montana, 1976. 


\section{REFEKENCES}

Alberti, R. E., \& Emmons, M. L. Your perfect right: A

guide to assertive behavior. San Luis Obispo,

California: Impact, 1974 .

Aronson, E., \& Carlsmith, J.M. Experimentation in social

psychology. In G. Lindzey \& E. Aronson, (Eds.),

Handbook of social psychology, Vol. 2: Keading,

Massachusetts: Addison Wesley Publishing Co., 1969

Bates, H. D., \& Zimmerman, S. F. Toward the development of

a screening scale for assertive training. Psychological Feports, $1971,28,99-107$.

Bem, S. L. Probing the promise of androgeny. In A. G. Kaplan \& J. P. Bean, (Eds.), Beyond sex-role stereotypes: Readings towards a psychology of androgyny. Boston: Little, Brown \& Co., 1976.

Block, J., Von der Lippe, A., \& Block, J.H. Sex-role and socialization patterns: some personality concomitants and environmental' antecedents. Journal of Consulting and Clinical Psychology, 1973, 41, 321-341..

Borden, J. Witnessed aggression: Influence of an observeris sex and values on aggressive responding: Journal of Personality and Social Psychology, 1975, 31, 567-573. 
Broverman, I. U., Broverman, D. M., Clarkson, F. E.,

Rosenkrantz, P. S., \& Vogel, S. R. Sex-role stereotypes and clinical judgements of mental health. Journal of Consulting and Clinical Psychology, 1970, 34, 1-7.

Buss, A. H. Aggression pays. In J. Singer (Ed.), The control of aggression and violence. New York: Academic Press, 1971.

Buss, A. H. Instrumentality of aggression, feedback, and frustration as determinants of physical aggression. Journal of Personality and Social Pyschology, 1966, 3, 153-162.

Buss, A. H. Physical aggression in relation to different frustrations. Journal of Abnormal and Social Psychology, 1963, 61, 1-7.

Deaux, K. The behavior of women and men. Monterey, California Brooks/Cole, 1976.

Deaux, $K$. Horn honking at the intersection: A replication and extension. Journal of Social Psychology, $1971,84,159-160$.

Doob, A. N., \& Gross, A. E. Status of frustrator as an inhibitor of horn-honking responses. Journal of Social. Psychology, 1968, 76, 213-218. 
Eisler, K. M., Herson, M., Miller, P. M., \& Blanchard, E. B. Situational determinants of assertive behaviors. Journal of Consulting and Clinical Psychology, $1975,43,330-340$.

Friedman, P. H. The effects of modeling and role playing on assertive behavior (Doctoral dissertation, University of Wisconsin, 1968). Dissertation Abstracts, 1969, 299, 3557 B-4901 B (University Microfilms No. 69-912) Galassi, J. P., DeLeo, J. S., Galassi, M. D., \& Bastien, S. The college self-expression scale: A measure of assertiveness. Behavior Therapy, 1974, 5, 165-171. Gambrill, E. D., \& Kichey, C. A. An assertion inventory f'or use in assessment and research. : Behavior. Therapy, $1975, \underline{6}, 550-561$.

Goldberg, P. A., Gottesdiener, M., \& Abramson, P. Another put-down of women? Attractiveness as a function of support for the feminist movement. Journal of Personality and Social Psychology, 1975, 32, i13-116. Goldfried, M.K., \& Sprafkin, J. N. Behavioral personality assessment. Morristown, N. J.: General Learning Press, 1974.

Goldstein, A. P., Martens, J., Hubben, J., Van Belle, H. A., Schaaf, W., Weirsma, H. \& Goedhart, A. The use of modelling to increase independent behavior. Behaviour Research and Therapy, 1973, 11, 31-42. 
Harris, B. Field studies of modeled aggression. Journal of Social Psychology, 1973, 89, 131-139.

Kagan, J. Acquisition and significance of sex typing and sex-role identity. In $M$. L. Hoffman \& L. W. Hoffman (Eds.), keview of child development research, Vol. 1. New York: Kussel Sage Foundation, 1964.

Kaleta, K. J. \& Buss, A. H. Aggression intensity and femininity of the victim. Paper presented at meeting of Eaștern Psychological Associaltion, May, 1973.

Kohlberg, L. A cognitive-developmental analysis of children's sex-role concepts and attitudes. In E. E. Maccoby (Ed.), The development of sex differences. Stanford: Stanford University Press, 1966. Lawrence, P.S. The assessment and modification of assertive behavior (Doctoral dissertation, Arizona State University, 1970). Dissertation Abstracts International, 1970, 31, I B-971B University Microfilms No. 70-11, 888 .

Lazarus, A. A. Behavior therapy and beyond. New York: McGraw Hill, 1971.

Lazarus, A. A. On assertive behavior: A brief note. Behavior Therapy, 1973, 4, 697-699.

Maccoby, E. E. \& Jacklin, C.N. The psychology of sex differences. Stanford: Stanford University Press, 1974. 
McFall, K. M. \& Lillesand, D. B. Behavior rehearsal with modeling and coaching in assertion training. Journal of Abnormal Psychology, 1971, 27, 313-323. McFall, K. M. \& Marston, A. K. An experimental investigation of behavior rehearsal in assertive training. Journal of Abnormal Psychology, 1970, 70, 295-303. McFal1, K. M., \& Twentyman, C. T. Four experiments on the relative contributions of rehearsal, modeling, and coaching to assertion training. Journal of Abnorma1 Psychology, 1973, 1ㅣ, 199-218. Mischel, W. Sex-typing and socialization. In P. H. Mussen (Ed.), Carmichael's manual of child psychology. New York: Wiley, 1970.

Mischel, W. A social learning view of sex differences in behavior. In E. E. Maccoby (E'd.), The development of sex differences. Stanford: Stanford University Press, 1966.

Kichmond, V. P., \& Kobertson, D. L. Women's liberation in interpersonal relations, Journal of Communication, $1977,27,42-45$.

Kathus, S. A. A 30-item schedule for assessing assertive behavior. Behavior Therapy, 1973, 4, 398-406. Rish, A. K. \& Schrooder, H. E. Kesearch issues in assertiveness training. Psychological Bulletin, 1976, 83, $1081-1096$. 
Fosenkrantz, P., Vogel, S., Bee, H., Broverman, I., \&.

Broverman, D. Sex-role stereotypes and self-concepts in college students. Journal of Consulting and Clinical Psychology, 1968, 32, 287-295.

Hotter, J. B. Social learning and clinical psychology.

New York: Prentice-Hall, Inc., 1954.

Salter, A. Conditioned reflex therapy. New York:

Farrar, Strauss, 1949.

Shortell, J. R. \& Biller, H. B. Aggression in children as

a function of sex of subject and sex of opponent.

Developmental Psychology, 1970, 3, 143-144.

Speilberger, C. D., Gorsuch, R. L., \& Lushene, R. Manual

for the state-trait anxiety inventory. Palo Alto,

California: Consulting Psychologists Press, 1970.

Taylor, P., \& Epstein, S. Aggression as a function of

the interaction of the sex of the aggressor and the.

sex of the victim. Journal of Personality, 1967, 35,

474-486.

Weinman, B., Gelbart, P., Wallace, M., \& Post, M. Inducing assertive behavior in chronic schizophrenics: A comparison of socio-environmental, desensitization, and relaxation therapies. Journal of Consulting and Clinical Psychology, 1972, 39, 246-252.

Wolpe, J. Psychotherapy by reciprocal inhibition. Stanford: Stanford University Press, 1958. 
Wolpe, J., \& Lazarus, A. A. Behavior Therapy Techninues, New York: Pergamon Press, 1966. Young, D. M., Beier, E. G., Beier, P., \& Barton, C. Is chivalry dead? Journal of Communication, 1975, 25 , $57-64$. 


\section{TABLE I}

Analysis of Variance:

\section{Unobtrusive Measure of Assertion}

Source

Between

$\begin{array}{lllll}\text { Attitude } & 3.82813 & 1 & 3.82813 & 1.138 \\ \text { Appearance } & 15.7531 & 1 & 15.7531 & 4.683 \% \\ \text { Behavior } & .903125 & 1 & .903125 & .269 \\ \text { Attitude x Appearance } & .0281251 & 1 & .0281251 & .008 \\ \text { Attitude x Behavior } & .003125 & 1 & .003125 & .001 \\ \text { Appearance x Behavior } & 16.6531 & 1 & 16.6531 & 4.951 \% \\ \text { Attitude x Appearance x Behavior } & .378125 & 1 & .378125 & .1 .12 \\ \text { ithin } & 242.175 & 72 & 3.3654 & \\ \text { tal } & 279.722 & & & \end{array}$

$\underline{S S} \quad \underline{\mathrm{df}} \quad \underline{\mathrm{F}}$

F 
TABLE 2

Mean Assertion Scores of Subjects Grouped by Levels of Factors:

Subjects' Attitude Toward Women

Traditional

Pro-Feminist

Appearance of Confederate*

Feminine

Non-Feminine

Behavior of Confederate

Feminine

Non-Feminine
2.48

3.03

2.60

3.13

3.26

2.71

$* 0.05$ 
TABLE 3

Mean Assertion Scores for Subjects Grouped by Appearance, Behavior, and Subjects' Attitudes

Subject Group Feminine Behavior Non-Feminine Behavior

Traditional

Feminine Appearance

1.85

2.70

Non-Fem. Appearance

3.75

2.10

Pro-Feminist

Feminine Appearance

2.40

2.95

Non-Fem. Appearance

$4 \cdot 10$

3.10 
TABLE 4

Analysis of Variance:

Anxiety Measure

Source

Between

Attitude
Assertion
Attitude $\times$ Assertion
Within
Total.

$\underline{\mathrm{SS}}$

400.00 7225.00 3025.00

390450

401100 df

$\underline{\text { MS }}$

$\underline{F}$

$400.00 \quad .061$

$1 \quad 7225.00 \quad 1.110$

1. 3025.00

.465

$60 \quad 6507.50$ 


\section{Figure Caption}

Figure 1. Mean ratings of assertion showing the interaction effect of the behavior factor with the appearance factor. 


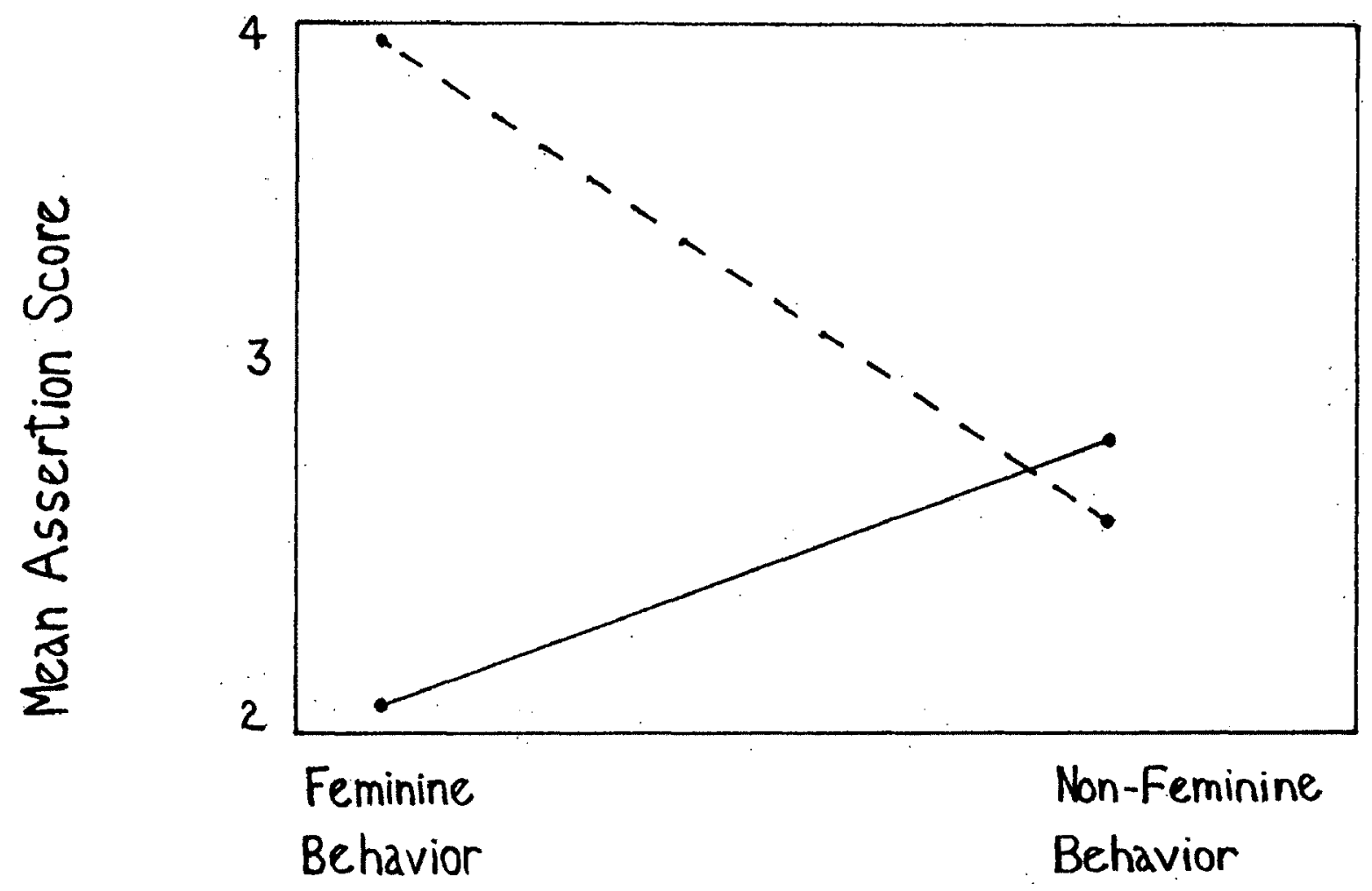

Feminine Appearance

$\ldots \ldots$ Non-Feminine Appearance 
brary is always losing the books. What do you want to know now?

E: Okay, where were we? Could you tell me what your favorite course in high school was?

S: Science. All the Science classes.

E: Fine. And what is your major now?

S: I'm a math major:

E: What do you plan to do when you finish college?

S: I'd like to find some sort of job where $I$ can apply my math. Maybe working for some researchers, something like that.

E: Okay. Ihat's all I need to know for now. Would you please take this questionnaire into the next room and fill it out. When you're finished; bring it back here.

S: How long does it take to fill out?

E: Most people take 5-10 minutes, but don't feel like you have to rush for my sake.

General Directions

Start into the script as the subject enters the room. After the script is finished, the confederate goes into the other room and starts filling out the questionnaire. The Experimenter then gives a rationale to the subject, saying: "We: are interested in comparing how people evaluate themselves. in general with how they see themselves at any given time. We think this may have a connection to a person's interests and goals. First I need to ask you a few questions about your experiences with school and your future plans. Then I have a questionnaire I'd like you to fill out that has to do with evaluating your feelings."

Show the subject the questionnaire and explain the directions to him. Then send him into the other room. When he comes out, take the questionnaire from him and direct him into the debriefing room. 
Appendix $B$

The following rating scales were administered to establish the validity of the feminine and nonfeminine behavior scenes and appearances used:

I. Please rate the behavior of the woman subject you have just seen on the following five characteristics:

1. Refrains from using harsh language

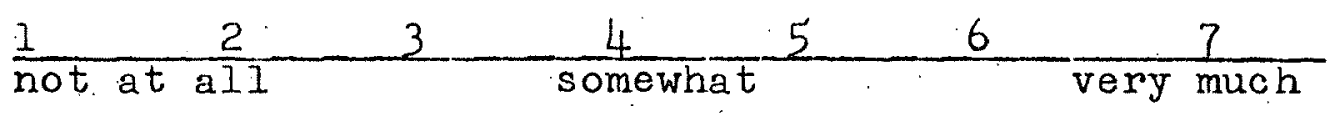

2. Quiet, soft-spoken

$\frac{1}{\text { not at all }} \frac{2}{3} \quad \frac{4}{5} \quad 6 \quad \frac{7}{\text { somewhat }}$

3. Tender, expresses tender feolings

$\frac{1}{\text { not at a a }}-3-\frac{4}{\text { somewhat }} 5-6-\frac{7}{\text { very }} \frac{7}{\text { much }}$

4. Aware of feelings of others, sympathetic, understanding $\frac{1}{\text { not at }} \frac{2}{\text { alI }}-3-\frac{4}{\text { somewhat }} \cdot 5 \quad 6-\frac{7}{\text { very much }}$

5. Appreciates art and literature

$\frac{1}{\text { not at all }} \frac{2}{3} \quad \frac{4}{5}-6 \quad 6 \quad \frac{7}{\text { very much }}$

II. Please rate the extent to which the subject you have just seen exhibits a traditionally feminine appearance.

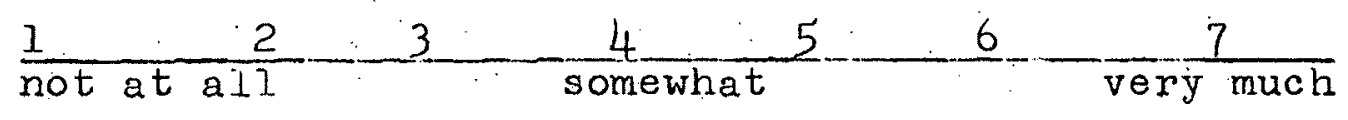


Appendix C

Sign Up Sheet for Subjects (A Traditional, B ProFeminist)

Self-Awareness and Vocational Interests Experiment

This experiment is looking at possible correlations between a person's degree of self-awareness and various aspects of vocational interest, both at school and concerning future career plans. It involves filling out a short questionnaire and having a brief interview.

$\begin{aligned} & \text { Day One } \\ & 9: 00 \mathrm{~A} \\ & 9: 30 \mathrm{~B} \\ & 10: 00 \mathrm{~A} \\ & 10: 30 \mathrm{~B}\end{aligned}$

Group A

Andrews, $B$. Cook, C. etc.
Group B

Alsatian, D. Bonaparte, N. 
Appendix $D$

Schedule of Treatments and Subject Groups (n 80$)$

Day 1

Fem. Appear

$A-F e m . ~ A c t$

$B-F e m$. Act

$A-N$. Fem. Act

$B-N$. Fem. Act

A-Fem Act

$B-F e m$ Act

$A-N$. Fem. Act

$B-N . F e m . \Lambda c t$

$A-F e m$. Act

B-Fem: Act
Day 2

N. F'em. Appear.

$B-N$. Fem. Act

A $-\mathrm{N}$. Fem. Act

$B-F e m$. Act

$A-$ Fem. Act

$B-N$. Fem. Act

$A-N$. Fem. Act

$B-F^{\prime} e m$. Act

A-Fem. Act

B-N. Fem: Act

$A-N$. Fem. Act
Day 3...

Day 8

Fem. Appear.

$A \div F^{3}$ em. Act

$\mathrm{B}-\mathrm{Fem}$. Act

$A-N$. Fem. Act

$B-N$. Fem. Act

A-Fem. Act

$B$-Fem. Act

A - N. Fem, Act

$B-N$. Fem. Act

$A-r^{\prime} e m$. Act

$B-F e m$. Act
N. Fem. Appear

$B-\dot{N}$. Fem. Act $A-N$. Fem. Act

B-Fem. Act A-Fem. Act $B-N$. Fem. Act A-N. Fem: Act

B-Fem. Act A-Fem. Act

Br N. Fem. Act $A-N$. Fem. Act 
Appendix E'

Validation questionnaire and Attitude 'lowards Women ScaleShort Version

Sex: M F

Please circle the number wricn most closely represents your response to the following statements.

Indicate your attitude towards the role of women:

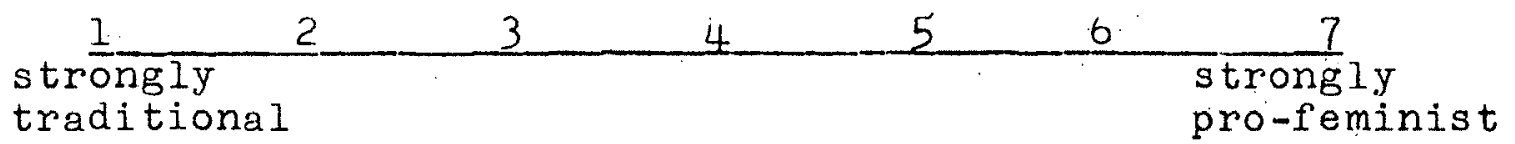

Indicate your attitude towards the proposed amendment to the US Constitution concerning erual rights. for women:

$\begin{array}{lllll}\frac{1}{\text { strongly support }} & 3 & 4 & 5 & 6\end{array}$

If you are in a situation where you are in conflict with someone, are you easier on the other person if it is a woman rather than a man?.

\begin{tabular}{|c|c|c|c|c|c|}
\hline 1 & 2 & 3 & 4 & 5 & 7 \\
\hline $\begin{array}{l}\text { Imost } \\
\text { hever }\end{array}$ & & sometimes & & frequently & $\begin{array}{l}\text { almost } \\
\text { always }\end{array}$ \\
\hline
\end{tabular}

The statements listed below describe attitudes toward the role of women in society that different people have. There are no right. or wrong answers, only opinions. You are asked to express your feeling about each statement by indicating whether you $(\Lambda)$ agree strongly, (B) agree mildly, (C) disagreo mildly, or (D) disagree strongly. Please indicate your opinion by marking A, B, C, or D on the line before each statement.

A* 1: Swearing and obscenity are more repulsive in the speech of a woman than of a man.

D. 2. Women should take increasing responsibility for leadership in solving the intellectual and social problems of the day.

D 3. Both husband and wife should be allowed the same grounds for divorce.

A 4. Telling dirty jokes should be mostly a masculine prerogative.

$\Lambda$ 5. Intoxication among women is worse than Intoxication amorig men. 
D 6. Under modern economic conditions with women being active outside the home, men should share in household tasks such as washing dishes and doing the laundry.

D 7. It is insulting to women to have the "obey" clause remain in the marriage service.

D 8. There should be a strict merit system in job appointment and promotion without regard to sex.

D 9. A woman should be as free as a man to propose marriage.

A 10. Women should worry less about their rights and more about becoming good wives and mothers.

D 11\% Women earning as much as their dates should bear equally the expense when they go out together.

D 12. Women snould assume their rightful place in business and all the profession along with men,

A 13. A woman should not expect to go to exactly the same places or to have quite the same freedom of action as a man.

A 14. Sons in a family should be given more encouragement to go to college than daughters.

A 15. It is ridiculous for a woman to run a locomotive and for a man to darn socks.

A 16. In general, the father should have greater authority than the mother in the bringing up of children.

A 17. Women should be encouraged not to become sexualiy intimate with anyone before marriage, even their fiances.

D 18. The husband should not be favored by law over the wife in the disposal of family property or income.

A 19. Womer should be concerned with their duties of childbearing and house tending, rather than with desires for professional and business careers.

A 20. The intellectual leadership of a community should be largely in the hands of men. 
D 21. Economic and social freedom is worth far more to women than acceptance of the ideal of femininity which has been. set up by men.

A 22. On the average, women should be regarded as less capable of contributing to economic production than are men.

A 23. There are many jobs in which men should be given preference over women in being hired or promoted.

D 24. Women should be given equal opportunity with men for apprenticeship in the various trades.

D 25. The modern girl is entitled to the same freedom from regulation and control that is given to the modern boy.

*The most conservative alternative, scored 0 , is shown. Each item is given a score from 0 to 3 , with 3 being the most contemprorary, profeminist response. 